\title{
Resistência à podridão parda em pessegueiro
}

\author{
Juliano dos Santos ( $\left.{ }^{1}\right)$; Maria do Carmo Bassols Raseira $\left({ }^{1 *}\right)$; Ilisandra Zanandrea $\left({ }^{2}\right)$ \\ (') Embrapa Clima Temperado, Rod. BR 392, km 78, 96010-971 Pelotas (RS), Brasil. \\ (2) Universidade Federal de Pelotas, Instituto de Biologia, 96010-900 Capão do Leão (RS), Brasil. \\ (*) Autora correspondente: maria.bassols@cpact.embrapa.br
}

Recebido: 15/jul./2011; Aceito: 6/fev./2012

\begin{abstract}
Resumo
A podridão parda, causada por Monilinia fructicola, é a mais importante doença fúngica do pessegueiro, principalmente em áreas quentes e úmidas, como a região produtora de pêssegos no Sul do Brasil. A resistência genética é a forma mais eficiente de controle da doença, além de reduzir o custo de produção e o impacto ambiental. A cultivar Bolinha, considerada padrão de resistência à doença, produz frutos de baixa qualidade e suas flores não têm a mesma resistência ao fungo. Este trabalho teve como objetivo buscar novas fontes de resistência a esta doença. Além da cultivar Bolinha, foram submetidos à inoculação com suspensão de $1 \times 10^{5}$ conídios $\mathrm{mL}^{-1}$ do patógeno, flores de 11 seleções de pessegueiro, frutos de 12 seleções e 20 plantas de cinco "seedlings" oriundos de hibridações. Os resultados indicaram que a seleção Conserva 930 e a cultivar Jubileu foram as que tiveram maior nível de resistência nas flores. Frutos das seleções Conserva 1798, Conserva 1596, Conserva 1218 e Cascata 1493 proporcionaram níveis de resistência semelhantes aos da cultivar Bolinha, e destas, apenas a Conserva 1798 manteve o mesmo desempenho em estádio mais avançado de infecção por M. fructicola.
\end{abstract}

Palavras-chave: Monilinia fructicola, Prunus persica, queima de flores, podridão de frutos.

\section{Resistance to brown rot in peach plants}

\section{Abstract}

Brown rot, caused by Monilinia fructicola, is the most important peach disease, especially in warm humid areas such as the production area in Southern Brazil. Genetic resistance is the most efficient way for controlling this disease, reducing production costs and environmental problems. The Bolinha cultivar, considered as resistant standard, produces fruits of low quality and is not resistant to blossom blight. The objective of this study was to find new resistance sources to brown rot. Besides Bolinha cultivar, flowers of 11 selections, fruits of 12 selections, and 20 seedlings from hybrid progenies were inoculated with a suspension of conidia of M. fructicola. The results indicated that Conserva 930 and Jubileu cultivar showed the highest levels of blossom blight resistance. Fruits of the selections Conserva 1798, Conserva 1596, Conserva 1218, and Cascata 1493 had resistance levels very similar to the ones of Bolinha cultivar after 72 hours of inoculation. However, only Conserva 1798 maintained the same performance at advanced stages of M. fructicola infection.

Key words: Monilinia fructicola, Prunus persica, blossom blight, fruit rot.

\section{INTRODUÇÃO}

A cultura do pessegueiro (Prunus persica L. Batsch) vem crescendo em todo o mundo pelo aumento no consumo de frutos in natura e pela sua utilidade para industrialização e comercialização sob forma de sucos e enlatados. O grande número de cultivares disponível garante uma produção qualitativa, além de adaptar-se para o cultivo em regióes de clima temperado e subtropical (RASEIRA e QUEZADA, 2003).

A podridão parda, causada pelo fungo Monilinia fructicola (Wint.) Honey, é a principal doença do pessegueiro no Brasil (MAY-DE-Mio et al., 2008). Na Região Sul do país, onde a quantidade de chuvas geralmente é alta durante o desenvolvimento dos frutos, a incidência da doença tem sido elevada nos últimos anos (Tibola et al., 2005; MaY-De-Mio et al., 2008).
O fungo $M$. fructicola tem duas fases de infecção bem conhecidas: uma no período de floração, causando queima de pétalas e cancro em ramos, e outra nos estágios finais de frutificação, causando a podridão dos frutos em pré e pós-colheita (HoNg et al., 1997). Sob condiçóes climáticas favoráveis, ascósporos e conídios produzidos pelo inóculo primário são capazes de infectar as flores causando queima e queda de pétalas e, consequente, redução da produção. Sob condições desfavoráveis, a infecção pode permanecer latente nos frutos, ocasionando podridão nas fases de pré e pós-colheita (Hong et al., 2007). A coincidência de condiçôes ambientais favoráveis à doença com o período de frutificação favorece a podridão de frutos ainda na planta, ocasionando frutos mumificados que podem servir como fonte de inóculo secundário (HoNG et al., 2007). 
As recomendaçóes para o controle da doença no Brasil são baseadas em tratamentos protetores através da utilização de fungicidas, principalmente durante a floraçáo e nos estádios de pré-colheita (BALARDin et al., 1994; Andrade e Matos, 1996). Esse tipo de controle, porém, além de causar desequilíbrio ambiental, eleva o custo de produção e, muitas vezes, não oferece um controle eficiente em função da grande quantidade de inóculo que pode estar presente no pomar, das condiçóes climáticas durante o ciclo produtivo ou do manejo cultural (BALARDin et al., 1994).

A utilização da resistência genética à podridão parda tem sido limitada pela inexistência, até o presente, de cultivares resistentes (Moreira e MaY-De-Mio, 2007). Alguns trabalhos têm demonstrado que a cultivar sul-americana Bolinha exibe nível de resistência em frutos relativamente maior do que outras cultivares (FeLICIANo et al., 1987, Gradziel et al., 1998, 2003; WaGNER JúNior, 2005; Lee e Bostock, 2007), o qual se acredita que esteja relacionado com a espessura da cutícula, compactação das células da epiderme e produção de compostos fenólicos. Porém, a baixa qualidade dos frutos aliada ao problema da queda precoce não estimulam seu cultivo.

Portanto, é fundamental que programas de melhoramento genético de pessegueiro busquem genótipos com elevado grau de resistência à podridão parda. A combinação de genótipos promissores com outros de características desejáveis como qualidade de fruto, por exemplo, está sendo testada e avaliada no programa de melhoramento da Embrapa Clima Temperado, visando à resistência à podridão parda do pessegueiro. Levando em consideração o grande número de cruzamentos e progênies obtidas e visando otimizar e agilizar o trabalho dos melhoristas, também é necessário aprimorar uma técnica que seja fácil e rápida para avaliação de grande número de genótipos.

Assim, objetivou-se com este trabalho avaliar o potencial de diferentes genótipos de pessegueiro quanto à resistência a $M$. fructicola visando à inserção de genótipos promissores em programas de melhoramento para resistência à podridão parda do pessegueiro. Além disso, testar a eficiência do método de inoculação em frutos para diferenciar as progênies quanto à resistência à $M$. fructicola.

\section{MATERIAL E MÉTODOS}

\section{Avaliação da incidência da queima das flores}

Ramos de plantas em produçáo contendo flores em estádio de botão rosado (estádios de botão floral adaptados de LAYNe e BASSI, 2008), foram coletados no pomar da Embrapa Clima Temperado em 2010. As cultivares e as seleçôes avaliadas estáo listadas na tabela 1 . Flores abertas foram descartadas e os ramos mantidos em água e colocados em câmara fria a $4 \pm 1^{\circ} \mathrm{C}$ por 24 horas para uniformizar a floração. Quando as flores atingiram o estádio de balâo (estádios de botão floral adaptados de LAYNE e BASSI, 2008), essas foram submetidas à inoculação com uma suspensão de $1 \times 10^{5}$ conídios $/ \mathrm{mL}$ de $M$. fructicola, obtidos de cultura pura em meio batata-dextrose-ágar (BDA). Flores abertas foram retiradas dos ramos antes da inoculação que foi realizada por aspersão com auxilio de um borrifador manual. Como testemunhas foram utilizadas ramos com aspersão de água esterilizada.

O experimento foi desenvolvido em delineamento inteiramente ao acaso em esquema fatorial $11 \times 2$ sendo 11 genótipos e dois tipos de inoculação (inoculação ou não com o patógeno) e três repetições. A parcela experimental foi composta de três ramos. Logo após a inoculação, todos os ramos foram colocados em câmara de crescimento (I-60L, Percival Scientific, Inc., Perry, IA, EUA) a $25 \pm 1^{\circ} \mathrm{C}$ sob câmara úmida por 72 horas. Após este período, foi avaliada a incidência da queima nas pétalas que consistiu no percentual de flores com esse tipo de sintoma por ramo. A infecção natural foi estimada pela avaliação dos ramos pulverizados com água (tratamento controle).

\section{Avaliação da severidade da podridão parda em frutos}

Cultivares e seleçóes da safra 2010/2011: frutos verdes (LAYNe e BASSI, 2008) das cultivares e seleçóes estudadas (Tabela 1) foram ensacados na planta para evitar danos de insetos. Quando maduros, foram colhidos e submetidos à desinfestação superficial com hipoclorito de sódio a $1 \%$. Quatro frutos desinfestados foram colocados em caixas plásticas transparentes. A inoculação foi feita através da deposição, em local previamente demarcado na superfície do fruto sem ferimento, de uma gota $(15 \mu \mathrm{L})$ de suspensão de $1 \times 10^{5}$ conídios $/ \mathrm{mL}$ de um isolado de $M$. fructicola obtido de um fruto com lesão contendo conídios. O escorrimento da gota pela superfície do fruto foi evitada.

Os frutos submetidos à inoculaçáo foram incubados em câmara de crescimento (I-60L, Percival Scientific, Inc., Perry, IA, EUA) a $25 \pm 1{ }^{\circ} \mathrm{C}$ e $75 \%$ de umidade. Avaliou-se o período de incubação a partir das primeiras 24 horas após a inoculação, o período latente (PL50) e o diâmetro da lesão. Para o diâmetro da lesão, foi utilizada a média de duas mediçốes perpendiculares realizadas diariamente com o auxílio de um paquímetro digital. O experimento foi montado em delineamento inteiramente casualisado com doze tratamentos e cinco repetiçôes, sendo quatro frutos por repetição.

Plantas originadas de cruzamentos da safra 2010/2011: frutos de plantas originadas de cruzamentos também foram avaliados e o método foi o mesmo utilizado para as cultivares e seleçóes. Foram avaliadas 20 plantas de cinco progênies diferentes: Jubileu x Fu-So-Tao (2006.198 - 8 plantas), Jade x Fu-So-Tao (2006.201 - 5 plantas), 
Maciel x Fu-So-Tao (2006.206 - 3 plantas), Diamante x Fu-So-Tao (2006.208 - 2 plantas), e Jade x Fu-So-Tao (2006.209 - 2 plantas). Estes cruzamentos foram escolhidos por terem como um dos genótipos parentais a cultivar Fu-So-Tao considerada boa fonte de resistência à podridão parda no continente asiático.

Por se tratar de um pomar novo, plantado em 2007, e com pequeno espaçamento entre e dentro das linhas, poucos frutos foram obtidos por planta. Como se tratam de "seedlings", plantas obtidas por reproduçáo sexuada, cada planta é um genótipo diferente. Assim, cada uma delas consistiu em um tratamento experimental, perfazendo um total de 20 tratamentos com 15 repetiçôes, sendo cada fruto uma repetição. Foi avaliado o diâmetro da lesão como a média de duas medições perpendiculares realizadas diariamente com o auxílio de um paquímetro digital. Os resultados foram comparados com os obtidos para a cultivar Bolinha considerada padráo de resistência à podridão parda.

\section{Análise estatística}

Os dados de incidência de queima de flores foram transformados para $\sqrt{ } \mathrm{x}+1$ para se adequarem à distribuição normal, segundo o teste de Shapiro-Wilk e submetidos à análise de variância. As médias foram comparadas pelo teste de Scott-Knott $(\mathrm{p}=0,05)$. O diâmetro médio das lesóes em frutos das cultivares e seleçóes foram submetidos a análise de variância e as médias foram comparadas pelo teste de Tukey $(\mathrm{p}=0,05)$. As análises foram realizadas utilizando-se o programa de análises estatísticas e planejamento de experimentos SISVAR (Ferreira, 2008).

Para as progênies dos cruzamentos devido ao pequeno número de indivíduos e de frutos por indivíduo, foi realizada apenas análise da frequência dos dados obtidos, as quais foram agrupadas em quatro classes ou grupos, a saber: classe 1 - frutos sem lesão visível; classe 2 - frutos com lesôes medindo de $0,1 \mathrm{a} 10 \mathrm{~mm}$ de diâmetro; classe 3 - frutos com lesôes medindo de 10,1 a $20 \mathrm{~mm}$ de diâmetro e classe 4 - frutos com lesôes maiores que $20 \mathrm{~mm}$ de diâmetro.

\section{RESULTADOS E DISCUSSÃO}

A incidência de flores com sintomas da queima de pétalas em ramos submetidos à inoculação com $M$. fructicola variou entre $26,3 \%$ e $100 \%$ entre os diferentes genótipos de pessegueiro (Tabela 1). Os genótipos mais afetados foram as seleçôes Conserva 947, Conserva 1556 e Conserva 1596 com incidência acima de 90\%. As flores da cultivar Bolinha não foram resistentes ao patógeno. A cultivar Jubileu e a seleção Conserva 930 destacaram-se
Tabela 1. Diâmetro médio da lesão da podridão parda em frutos de diferentes genótipos de pessegueiro em 72 e 96 horas após a inoculação com Monilinia fructicola

\begin{tabular}{|c|c|c|c|}
\hline \multirow{2}{*}{ Genótipos } & \multirow{2}{*}{$\begin{array}{l}\text { Diâmetro do } \\
\text { fruto }(\mathrm{mm})\end{array}$} & \multicolumn{2}{|c|}{ Diâmetro da lesão (mm) } \\
\hline & & $72 \mathrm{~h}$ & $96 \mathrm{~h}$ \\
\hline \multicolumn{4}{|l|}{ Seleções } \\
\hline Conserva 1806 & $60,18 b$ & $5,53 \mathrm{~d}$ & $24,50 \mathrm{c}$ \\
\hline Conserva 1798 & $61,69 \mathrm{a}$ & $0,83 d$ & $10,08 \mathrm{~d}$ \\
\hline Cascata 730 & $59,00 \mathrm{~b}$ & $9,49 \mathrm{c}$ & $25,80 \mathrm{c}$ \\
\hline Conserva 1218 & $61,70 \mathrm{a}$ & $4,10 d$ & $18,45 \mathrm{c}$ \\
\hline Cascata 1493 & $57,48 b$ & $5,45 d$ & $33,80 \mathrm{~b}$ \\
\hline Conserva 1596 & $62,14 \mathrm{a}$ & $5,24 \mathrm{~d}$ & $17,34 \mathrm{c}$ \\
\hline Conserva 930 & $65,73 \mathrm{a}$ & $28,49 b$ & $45,86 \mathrm{a}$ \\
\hline Conserva 1556 & $63,38 \mathrm{a}$ & $13,35 \mathrm{c}$ & $32,60 \mathrm{~b}$ \\
\hline Conserva 672 & $62,60 \mathrm{a}$ & $29,98 b$ & $44,01 \mathrm{a}$ \\
\hline \multicolumn{4}{|l|}{ Cultivares } \\
\hline Cerrito & $58,08 \mathrm{~b}$ & $34,87 \mathrm{a}$ & $47,69 \mathrm{a}$ \\
\hline Olímpia & $48,61 \mathrm{~d}$ & $24,51 b$ & $40,68 \mathrm{a}$ \\
\hline Bolinha & $55,26 c$ & $2,93 \mathrm{~d}$ & $9,45 d$ \\
\hline CV (\%) & 4,75 & 36,24 & 25,41 \\
\hline
\end{tabular}

$\mathrm{CV}=$ coeficiente de variaçắo. Médias seguidas das mesmas letras em cada coluna năo diferem entre si pelo teste de Tukey $(\mathrm{p}>0,05)$.

das demais por pelas as menores incidências da queima de pétalas (35,4 e 26,3\% respectivamente) (Tabela 1).

Quando as flores não submetidas à inoculação foram incubadas, houve o aparecimento dos sintomas da queima de pétalas em todos os genótipos testados, exceto na Conserva 1556 (Figura 1). Nas seleçóes Conserva 1596 e Conserva 947, os valores de incidência foram estatisticamente iguais àqueles verificados nas flores submetidas à inoculação. Nos demais, a incidência da podridáo parda nas flores náo infectadas foi sempre menor do que nas flores submetidas à inoculação (Tabela 1 ).

$\mathrm{Na}$ maioria dos genótipos de pessegueiro, o período de incubaçáo da podridão parda nos frutos foi de aproximadamente 72 horas após a inoculação. $\mathrm{Na}$ cultivar Cerrito e na seleção Conserva 930, o período de incubação foi mais curto, sendo observado sintoma da doença 24 horas após a inoculação em alguns frutos. O período latente ocorreu em 72 e 96 horas após a inoculação na maioria dos cultivares (dados não apresentados).

Nos frutos, o menor tamanho das lesóes foi observado na cultivar Bolinha e na seleção Conserva 1798, as quais se destacaram independentemente do tempo em que os frutos foram avaliados (Tabela 1). Merecem destaque ainda as seleçóes Conserva 1806, Conserva 1596, Conserva 1218 e Cascata 1493 com pouco desenvolvimento de lesōes até 72 horas após a inoculação de $M$. fructicola, ou seja, as lesóes foram relativamente pequenas até este período de tempo (Figura 2).

A resistência das flores dos diferentes genótipos de pessegueiro à podridão (queima) das pétalas foi bastante variável e não teve nenhuma relação com a resistência dos frutos. A alta incidência em flores não submetidas à 
inoculação verificada em alguns genótipos mostra que no período de floraçáo já existe a presença de inóculo no pomar. As diferenças de incidência da queima de pétalas nas flores naturalmente infectadas podem ser explicadas, além da resistência/suscetibilidade, pelas diferenças na época de floração (temporal) e posição geográfica dentro do pomar (espacial) entre os genótipos estudados.

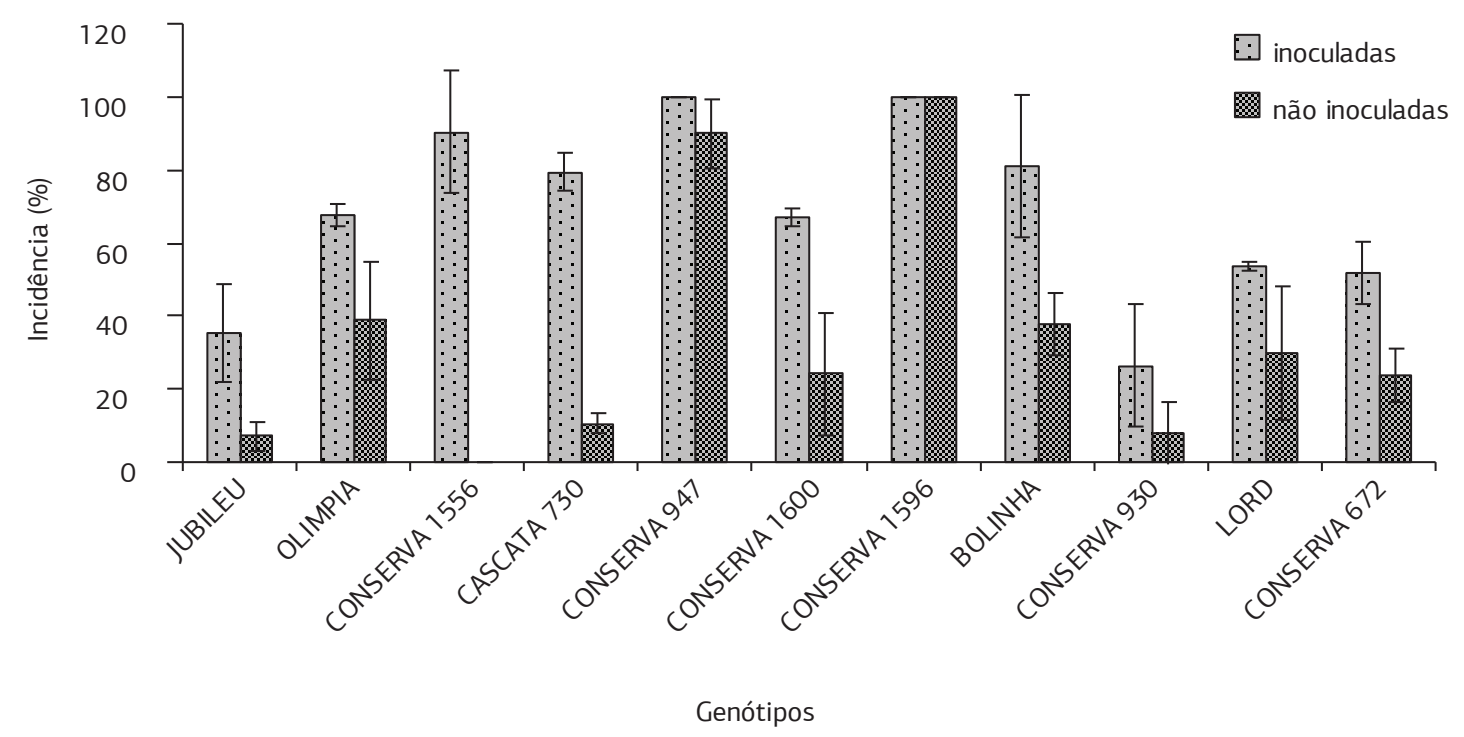

Figura 1. Incidência da queima de flores em diferentes genótipos de pessegueiro submetidas à inoculação ou não com Monilinia fructicola mantidas a $25 \pm 1{ }^{\circ} \mathrm{C}$ sob câmara úmida por 72 horas. As barras verticais em cada coluna referem-se à estimativa do erro-padrão.
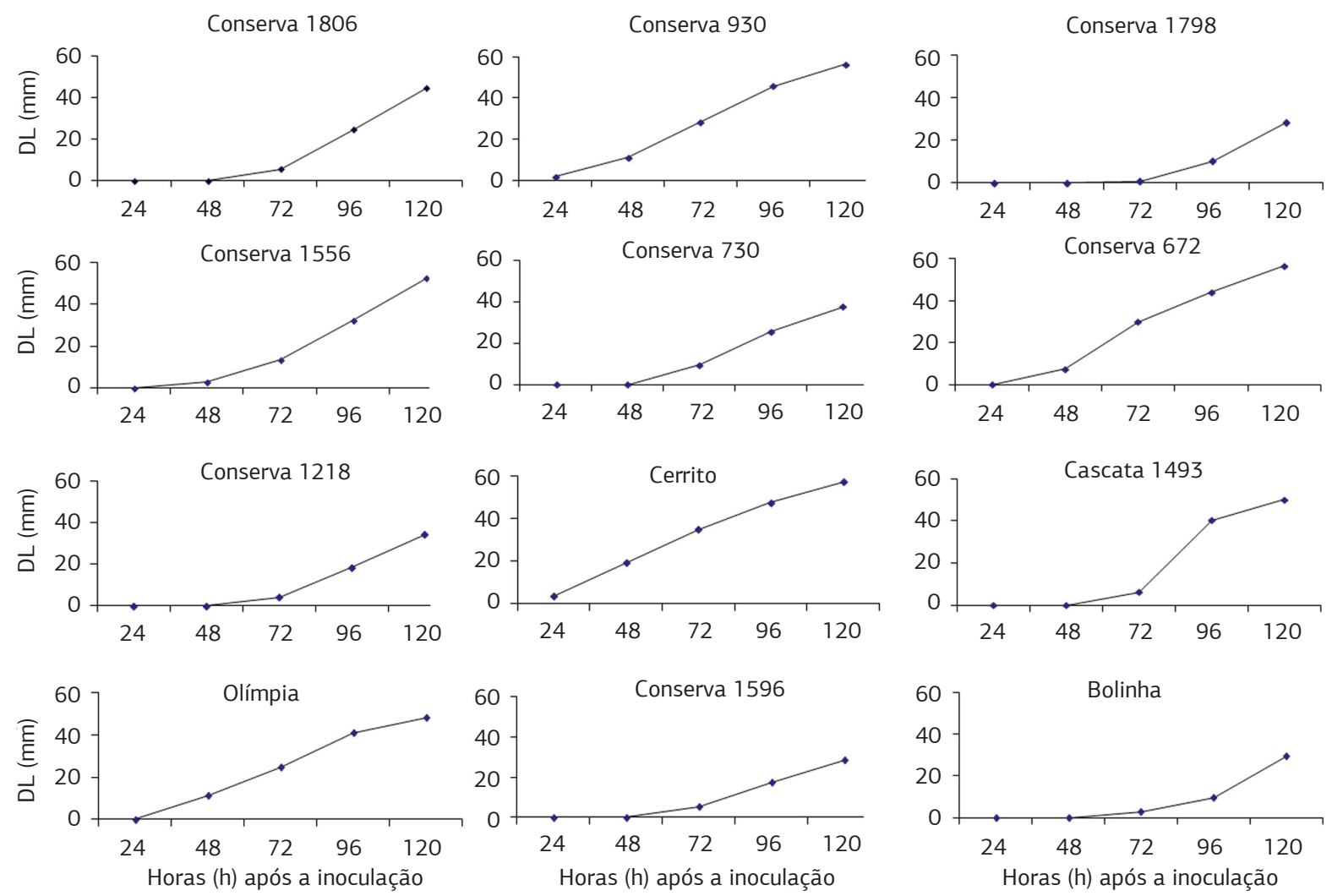

Figura 2. Curvas de progresso do diâmetro da lesão (DL) de podridão parda em frutos de diferentes genótipos de pessegueiro infectados com Monilinia fructicola. Cerrito, Olímpia e Bolinha são cultivares e os demais são seleçôes do programa de melhoramento da Embrapa Clima Temperado. Cada símbolo representa o valor médio de cinco repetições. 
Levando em consideração que a resistência à podridão parda é horizontal (WAGNER-Junior et al., 2008), os mecanismos envolvidos para conferir esta característica podem ser distintos em flores e frutos, o que explicaria não haver relação entre os resultados observados em ambas as partes da planta. Na cultivar Bolinha, por exemplo, que tem sido amplamente estudada como padrão de resistência a essa doença, houve baixo nível de resistência em flores ao contrário da reação em frutos.

A infecçấo das flores pelo patógeno pode causar perdas significativas na produção devido à redução no número de flores, prejudicando a frutificação efetiva, além de servir de fonte de inóculo para o período de frutificação (EMERY et al., 2000).
Além disso, flores que sobrevivem à infecção podem originar frutos contendo o patógeno que vai se manifestar causando danos nos períodos de colheita e pós-colheita (Moreira e MaY-De-Mio, 2007; KeSKe et al., 2010).

O método de inoculação em frutos foi eficiente para a distinção dos genótipos de pessegueiro principalmente às 72 e 96 horas após a inoculação (Tabela 1). Hong et al. (1998) avaliaram diferentes concentraçóes de inóculo e a influência de ferimento na infecção por $M$. fructicola em pêssego, ameixa e nectarina, verificando que o ferimento facilitou a infecção e a colonização do patógeno no fruto, produzindo sintomas mesmo com uma concentração menor de inóculo. Em pêssego, a estrutura da cutícula parece

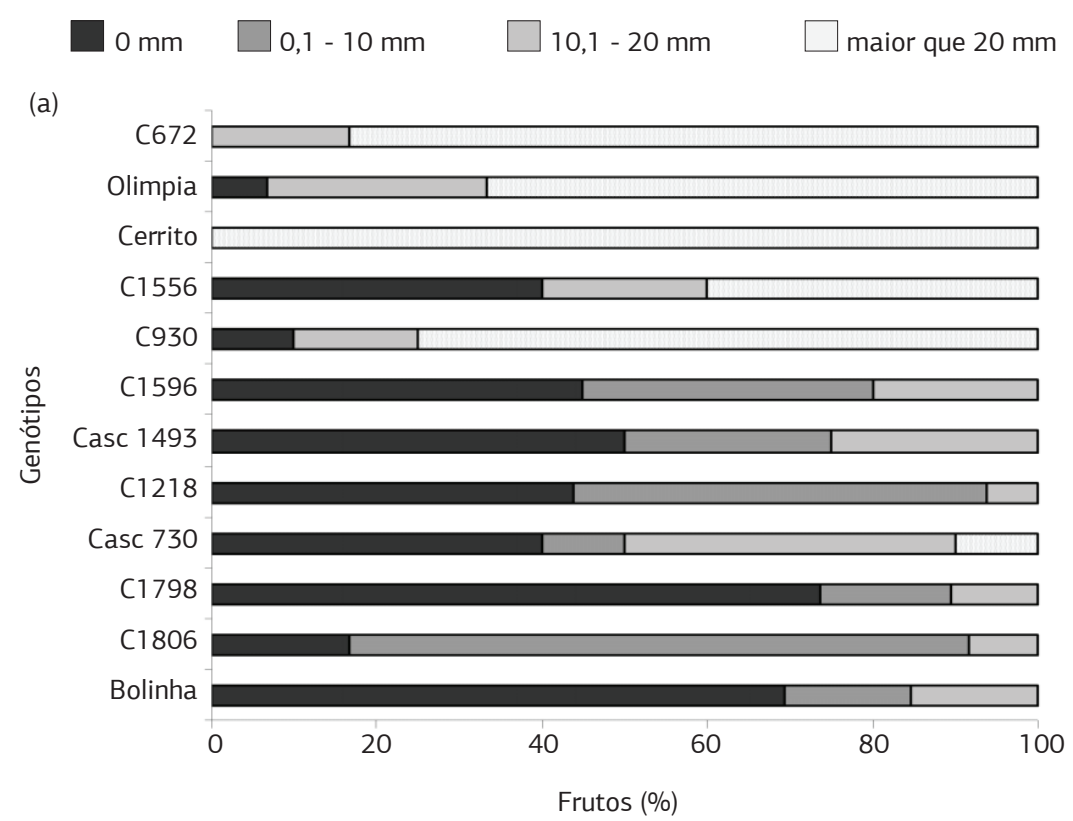

(b)

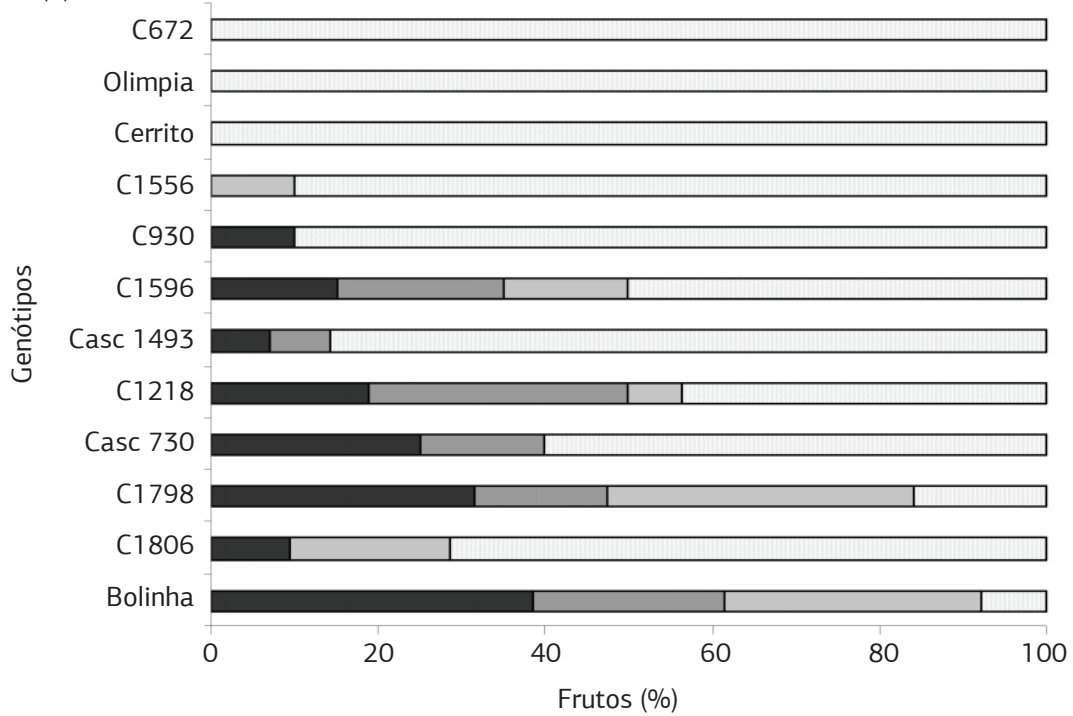

Figura 3. Percentual de frutos de algumas cultivares e seleções de pessegueiro com diferentes classes de severidade da podridão parda com base no diâmetro médio da lesão às 72 (a) e 96 horas (b) após inoculação com Monilinia fructicola. Cerrito, Olímpia e Bolinha são cultivares e os demais são seleçóes do programa de melhoramento da Embrapa Clima Temperado. 


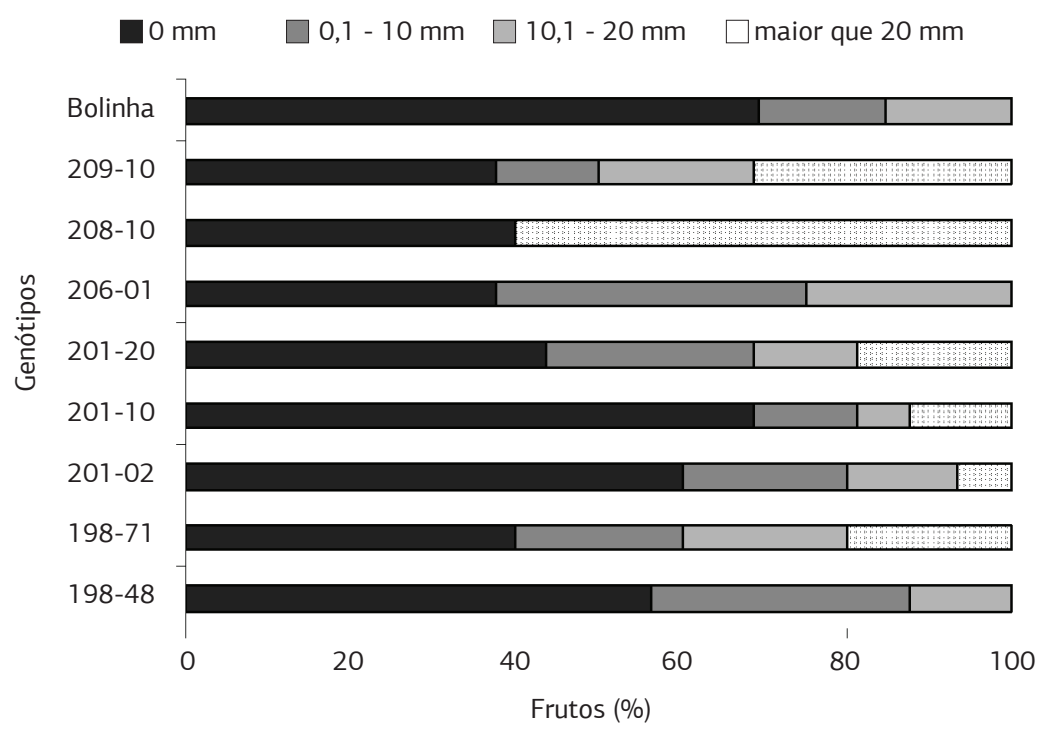

Figura 4. Percentual de frutos de pessegueiros, originados de cruzamentos, com diferentes classes de severidade da podridão parda com base no diâmetro médio da lesão, em comparação com a cultivar Bolinha, 72 horas após a inoculação com Monilinia fructicola.

estar relacionada à resistência à podridão parda (GRADZIEL et al., 1998), e assim, a avaliação da infecção do patógeno em frutos sem ferimentos torna-se indispensável.

Segundo Hong et al. (1998), frutos de pêssego sem ferimento também manifestaram sintomas evidenciados principalmente a partir da concentraçáo de $1 \times 10^{5}$ conidios $\mathrm{mL}^{-1}$. Esse fato demonstra que o patógeno tem eficiência de infecção extremamente alta e, em combinação com alta concentração de conídios na superfície do fruto, pode explicar a maior incidência da podridáo parda nos pomares no fim do ciclo em anos úmidos e também as elevadas perdas de frutos durante o armazenamento e transporte.

Assim como em outros trabalhos semelhantes (Feliciano et al., 1987; WaGNer JúNIOR, 2005; LeE e Bostock, 2007), a cultivar Bolinha foi a de maior nível de resistência à podridão parda em frutos. Além de espessa cutícula, nos frutos dessa cultivar observa-se maior concentração de compostos fenólicos na superfície, particularmente o ácido clorogênico do que em outros frutos com maturação similar de genótipos menos resistentes (LeE e Bostock, 2007).

Nas seleçóes Conserva 1798, Conserva 1806, Conserva 1596, Conserva 1218 e Cascata 1493, observou-se menor tamanho das lesôes até às 72 horas após a inoculação de $M$. fructicola. Nestes genótipos, é provável que a cutícula possa estar fortemente associada à resistência à podridáo parda, retardando a penetração do fungo na polpa até este período.

Levando em consideração que para a comercialização e o consumo dos frutos é importante a ausência de sintomas de podridão, o período de incubaçắo pode ser importante componente de resistência a ser considerado. Neste contexto, a cultivar Bolinha e a seleção Conserva 1798 podem ser promissoras, pois mesmo 72 horas após a inoculação, notava-se elevado percentual de frutos sem sintomas (Figura 3).

Para a eficiência de seleção de genótipos nos programas de melhoramento, é importante que os métodos de avaliação da podridão parda sejam rápidos e precisos permitindo, assim, avaliar grande número de genótipos em um curto espaço de tempo (Bassi et al., 1998). A técnica de inoculação artificial em frutos de pessegueiro sem ferimento prévio demonstrou ser eficiente neste aspecto, quando foram avaliados frutos de plantas originadas de cruzamentos. Dentre as plantas originadas de cruzamentos com resistência em frutos semelhante à cultivar Bolinha, destaca-se a 201-10. Porém, a precisão destes resultados pode ter sido afetada pelo fato de alguns genótipos terem produzido poucos frutos.

A utilização de mais de uma variável, neste caso, pode ser importante para a avaliação de resistência à podridão parda do pessegueiro. WALter et al. (2004) avaliaram algumas variáveis para "screening" da resistência à podridão parda em damasco (Prunus armeniaca): tamanho de lesão e esporulação em frutos com e sem ferimento prévio, infecção natural (infecção latente) e espessura da cutícula. Os autores relataram que a medida da área lesionada após 72 horas foi a variável que melhor descriminou os genótipos e teve alta correlação com a contagem de conídios que, por sua vez, mostrou ser uma avaliação bem mais laboriosa e demorada. O tamanho da lesão e a esporulação do patógeno em frutos não tiveram correlação com a infecção natural e a espessura da cutícula, sugerindo que a combinação de mais de uma variável pode elevar a eficiência pela busca por fontes de resistência.

WAGNER Junior et al. (2008) sugerem que a herança da resistência à podridão parda em pessegueiro é do tipo aditiva e de caráter poligênico. Assim, a característica de resistência ou suscetibilidade à podridão nos frutos pode ser bastante afetada por fatores ambientais e a existência de variabilidade genética é condição essencial para que o melhorista possa exercer seleção sobre qualquer população de plantas.

Neste trabalho, demonstrou-se que existem diferenças entre genótipos de pessegueiro quanto à reação à 
podridão parda, evidenciando a existência de variabilidade genética. Além da confirmação do potencial da cultivar Bolinha como fonte de resistência à podridão de frutos, alguns genótipos, tais como as seleçôes Conserva 1798, Conserva 1218 e Conserva 1806 e Conserva 1596, são promissores para o uso em programas de melhoramento genético. Apesar destes resultados, é importante avaliar esses genótipos em mais um ciclo de produção devido à variabilidade tanto na população genética do patógeno (FAN et al., 2010) quanto nas condiçôes ambientais que ocorrem em cada ciclo, as quais podem refletir nos níveis de resistência dos frutos.

\section{CONCLUSÃO}

O método de inoculação em frutos utilizado neste trabalho é eficiente para uma avaliação rápida da resistência à podridão parda em progênies de cruzamentos, sendo detectada diferença entre os genótipos de pessegueiro quanto à reação à podridáo parda em flores e frutos. Além da cultivar Bolinha, os genótipos Conserva 1798, Conserva 1218 e Conserva 1493 manifestam resistência satisfatória à podridão parda em frutos. Não se observa relação entre a resistência de flores e frutos à $M$. fructicola.

\section{REFERÊNCIAS}

ANDRADE, E.R.; MATOS, C.S. Controle químico de Monilinia fructicola em pêssego na pós-colheita. Fitopatologia Brasileira, v.21, p.301-303, 1996.

BALARDIN, R.S., BALARDIN, C.R.R.; CHAVES, L.C.S. Eficiência de fungicidas e diferentes doses no controle de Monilinia fructicola (Wint) sobre frutos do pessegueiro (Prunus persica var. vulgaris), em pós-colheita. Ciência Rural, v.24, p.15-17, 1994.

BASSI, D.; RIZZO, M.; CANTONI, L. Assaying brown rot [Monilinia laxa Aderh. Et Ruhl. (Honey)] susceptibility in peach cultivars and progeny. Acta Horticulturae, n.465, p.715-721, 1998.

EMERY, K.M.; MICHAILIDES, T.J.; SCHERM, H. Incidence of latent infection of immature peach fruit by Monilinia fructicola and relationship to brown rot in Georgia. Plant Disease, v.84, p.853$857,2000$.

FAN, J.Y.; GUO, L.Y.; XU, J.P.; LUO, Y.; MICHAILIDES, T.J. Genetic Diversity of Populations of Monilinia fructicola (Fungi, Ascomycota, Helotiales) from China. Journal of Eukaryotic Microbiology, v.57, p.206-212, 2010.

FELICIANO, A.; FELICIANO, A.J.; OGAWA, J.M. Monilinia fructicola resistance in peach cultivar Bolinha. Phytopathology, v.77, p.776-780, 1987.

FERREIRA, D.F. SISVAR: um programa para análises e ensino de estatística. Revista Symposium, v.6, p.36-41, 2008.
GRADZIEL, T.M.; THORPE, M.A.; BOSTOCK, R.M.; WILCOX, S.; MONETL, R. Breeding for brown rot (Monilinia fructicola) resistence in clingstone peach with emphasis on the role of fruit phenolics. Acta Horticulturae, n.465, p.161-170, 1998.

GRADZIEL, T.M.; BOSTOCK, R.M.; ADASKAVEG, J.E. Resistance to brown rot disease in Peach is determined by multiple structural and biochemical components. Acta Horticulture, n.622, p.347-352, 2003.

HONG, C.; HOLTZ, B.A.; MORGAN, D.P.; MICHAILIDES, T.J. Significance of thinned fruit as a source of the secondary inoculum of Monilinia fructicola in California nectarine orchards. Plant Disease, v.81, p.519-524, 1997.

HONG, C.; MICHAILIDES, T.J.; HOLTZ, B.A. Effects of wounding, inoculum density, and biological control agents on postharvest brown rot of stone fruits. Plant Disease, v.82, p.1210-1216, 1998.

KESKE, C.; AMORIM, L.; BIASI, L.A.; MAY-DE MIO, L.L. Queima das flores e podridão parda em pessegueiro sob sistema de cultivo orgânico. Ciência Rural, v.40, p.1682-1688, 2010.

LAYNE, D.R.; BASSI, D. (Ed.). The peach botany, production and uses. Wallingford, UK: CABI, 2008. 615p.

LEE, M. H.; BOSTOCK, R.M. Fruit exocarp phenols in relation to quiescence and development of Monilinia fructicola infections in Prunus spp.: A role for cellular redox? Phytopathology, v.97, p.269277, 2007.

MAY-DE-MIO, L.L.; MOREIRA, L.M.; MONTEIRO, L.B.; JUSTINIANO JÚNIOR, P.R. Infecção de Monilinia fructicola no período da floração e incidência de podridão parda em frutos de pessegueiro em dois sistemas de produção. Tropical Plant Pathology, v.33, p.173-180, 2008.

MOREIRA, L.M.; MAY-DE-MIO, L.L. Metodologia para detecção de infecçóes latentes de Monilinia fructicola em frutas de caroço. Ciência Rural, v.37, p.628-633, 2007.

RASEIRA, M.C.B.; QUEZADA, A.C. Pêssego: Produção. Brasília: EMBRAPA, Informaçôes Tecnológicas, Frutas do Brasil, 2003. 162p. (Boletim técnico 49)

TIBOLA, C.S.; FACHINELLO, J.C.; GRÜTZMACHER, A.D.; PICOLOTTO, L.; KRÜGER, L. Manejo de pragas e doenças na produçáo integrada e convencional de pêssegos. Revista Brasileira de Fruticultura, v.27, p.215-218, 2005.

WAGNER JÚNIOR, A.; RASEIRA, M.C.B.; PIEROBOM, C.R.; SILVA, J.B.; FRANZON, R.C. Avaliaçâo de diferentes genótipos de pessegueiro quanto à reação à Monilinia fructicola (Wint.) Honey em frutos. Revista Ceres, v.55, p.83-88, 2008.

WAGNER JÚNIOR, A.; RASEIRA, M.C.B.; PIEROBOM, C.R.; FORTES, J.F.; SILVA, J.B. Peach flower reaction to inoculation with Monilinia fructicola (Wint.) Honey. Journal of the Pomological Society, v.59, p.141-147, 2005.

WALTER, M.; MCLAREN, G.F.; FRASER, J.A.; FRAMPTON, C.M.; BOYD-WILSON, K.S.H.; PERRY, J.H. Methods of screening apricot fruit for resistance to brown rot caused by Monilinia spp. Australasian Plant Pathology, v.33, p.541-547, 2004. 